\title{
Evaluation of Subsurface Fatigue Crack Life in Forged Ti-6AI-4V Alloys at Cryogenic Temperatures
}

\author{
Makiko HAMADA and Osamu UMEZAWA
}

Department of Materials Science and Engineering, Graduate School of Engineering, Yokohama National University, 79-5 Tokiwadai, Hodogaya, Yokohama 240-8501 Japan. E-mail: umezawa@ynu.ac.jp

(Received on August 28, 2008; accepted on October 7, 2008)

\begin{abstract}
Fatigue crack growth modeling was performed for Ti-6Al-4V forged materials failed by subsurface crack generation at cryogenic temperatures. The modeling that was based on linear fracture mechanics under the Mode I condition provided a good estimate of the stress intensity range of subsurface or surface and fatigue crack growth, enabling the estimation of the crack propagation life. The fatigue crack growth rate calculated using the Paris rule, $d a / d N=C\left(\Delta K_{1}\right)^{m}$, almost corresponded to the one obtained from the analysis of the striation on the fracture surface. The calculated crack propagation life was less than a tenth of the number of cycles to failure over $10^{6}$. As a result, the subsurface crack initiation (Stage I crack generation) process consumed a large number of cycles to failure-as many as that at a lower stress level.
\end{abstract}

KEY WORDS: fractography; subsurface crack initiation; fatigue crack growth; titanium alloy.

\section{Introduction}

The fatigue process in metals is roughly divided into crack initiation (Stage I) and crack growth (Stage II) stages. Subsurface fatigue crack generation in the high-cycle regime occurs in some high-strength alloys such as titanium alloys, and the microstructure of the alloy, such as the grain morphology, grain size, and texture markedly affects crack generation. ${ }^{1}$ ) The initiation stage may involve a large number of cycles to failure and it controls the fatigue life of the alloy. It is difficult to experimentally evaluate crack generation life.

On the other hand, crack propagation life can be evaluated using linear fracture mechanics. The stress intensity values obtained by the integral of the Paris equation ${ }^{2)}$ can be adopted for modeling the fatigue crack growth. Moreover, a fatigue life model is available for calculating the crack growth; the model performs fractographic analyses using fatigue data. In order to evaluate the subsurface fatigue crack growth, the stress intensity of a growing crack in a complex stress field needs to be calculated dynamically. The influence function method employing a series of finite element analyses is suitable for determining the stress intensity around the crack front in detail; the stress varies along two directions, i.e., along the crack length and crack width, simultaneously. ${ }^{3)}$ Shiratori et al. $^{4)}$ have developed a software system "SCAN" based on linear fracture mechanics and have employed a simple transition model based on the standards in the ASME code (Section XI) ${ }^{5}$ ) and the WES 2805 Standard $^{6)}$ in the system for investigating subsurface cracks. Since the method is applied to a complex stress field, the stress intensity of a growing crack is dynamically calculated. Furthermore, it provides a reasonable resolution in the strength analysis of a cracked material.

Ti-6Al-4V alloys have typically shown subsurface fatigue failure and the subsurface crack initiation sites are clearly detected in the fracture surface at low temperatures. ${ }^{1)}$ As the maximum stress decreased, the morphology of the subsurface crack initiation sites was changed from consisting of one facet to of more than two facets. ${ }^{7}$ The facet was identified as a cracked $\alpha$ phase by comparing their chemical composition and morphology. The subsurface crack initiation sites were not perpendicular to the applied stress. Hence it was concluded that a microcrack initiates in an $\alpha$ grain, grows in the $\beta$ plate and extends into neighbor $\alpha$ phase and $\beta$ phase, until it finally forms the initiation site for a main fatigue crack. Kitagawa et al. ${ }^{8)}$ reported that the fatigue limit of the material containing preexisting defect was determined from the relationship between the defect size and threshold stress range. The dependence of the subsurface crack size on the applied stress, which is the condition for the transition from Stage I to Stage II, was concluded as the similar concept. ${ }^{7)}$ The threshold stress intensity range $\Delta K_{\text {th }}$ was found to be constant regardless of the test temperatures, i.e., at $4 \mathrm{~K}$ and $77 \mathrm{~K}$, and the microstructure. On the other hand, the fatigue crack growth behavior in Ti-6 $\mathrm{Al}-4 \mathrm{~V}$ has been studied by a number of investigators. ${ }^{9-14)}$ These studies show that fatigue crack growth in Ti-6Al-4V is influenced by the microstructure, stress ratio (crack closure phenomena), and the environment. Contrary to the belief that crack extension in Stage II occurs predominantly by Mode I, i.e. perpendicular to the loading direction, evidence of crystallographic crack extension, consistent with Neumann's alternating slip model $^{15)}$ for the formation of striations in single crystals was observed. 
In the present study, fatigue life of $\mathrm{Ti}-6 \mathrm{Al}-4 \mathrm{~V}$ forged (elongated $\alpha$ ) materials ${ }^{16)}$ that failed at cryogenic temperatures due to subsurface crack generation under the Mode I crack growth condition was evaluated using SCAN. The fatigue crack growth behavior of the materials was studied by modeling the crack growth and performing fractographic analyses. Various subsurface crack morphologies and sizes that were obtained in a previous experiment ${ }^{7)}$ were adopted to approximate the stress intensity range.

\section{Procedure}

\subsection{Materials and Samples}

The test materials were Ti-6Al-4V alloys of normal, extra-low interstitial (ELI), and super ELI (Sp.ELI) grades. The alloys were forged into a 30 -mm-thick plate in the $\alpha+\beta$ region at $1173 \mathrm{~K}$ and mill-annealed at $993 \mathrm{~K}$. The chemical compositions (in wt\%) of the normal, ELI and, Sp.ELI grades were 0.199 and 0.135 for $\mathrm{Fe}$ and $\mathrm{O} ; 0.200$ and 0.104 for $\mathrm{Fe}$ and $\mathrm{O}$; and 0.028 and 0.054 for $\mathrm{Fe}$ and $\mathrm{O}$, respectively. Their microstructure was of the colony type in which neighboring $\alpha$ platelets are aligned. Hourglass-type fatigue test specimens with a waist diameter of $4.5 \mathrm{~mm}$ were machined parallel to the RD (working direction). Load-controlled fatigue testing was carried out with the specimen immersed in either liquid helium at $4 \mathrm{~K}$ or liquid nitrogen at $\left.77 \mathrm{~K} .{ }^{16}\right)$ The sinusoidal loading was uniaxial with a minimum-to-maximum stress ratio $\left(\sigma_{\min } / \sigma_{\max }\right) R$ of 0.01 . The fractured samples ${ }^{7}$ that showed internal crack initiation were chosen for further study.

\subsection{Calculation of Stress Intensity Factor}

The simple transition model uses a database of influence coefficients $K_{i j}$ of both surface and subsurface elliptical cracks in a flat plate (Fig. 1). When several elements exist on the crack surface and occupy a node, the distributed unit stress at each node coincides with a configuration function. Applying the principle of superposition to the influence function method simplifies the stress analysis, as illustrated in Fig. 2. In the influence function method, the value of $K$ can be calculated by superposing the data of $K_{i j}$ and $\sigma_{j}$ through an algorithm that solves Eq. (1).

$$
K_{i}=\sum_{j=1}^{n} K_{i j} \sigma_{j}
$$

Here, $n$ is the number of nodes on the crack surface, $K_{i}$ is the stress intensity factor at the node I, and $K_{i j}$ is the influence coefficient of $K_{i}$ at the leading edge of the crack due to the distributed unit stress $\sigma_{j}$ applied at an arbitrary node $j$, as illustrated in Fig. 2(b). Details of the influence function method are given in Ref. 3).

To apply a stress distribution in the $y$-direction on the cross section of a virtual crack surface, as illustrated in Fig. 2 , the fifth-order polynomial form of $x$ was employed:

$$
\begin{aligned}
& \sigma(z, x)=\sigma_{0} \sigma_{1}(Z) \sigma_{2}(X) \\
& \sigma_{1}(Z)=1 \\
& \sigma_{2}(X)=G Y^{5}+H Y^{4}+I Y^{3}+J Y^{2}+K Y+L
\end{aligned}
$$

where $Z=z / t$ and $X=x / t$ are the normalized coordinates, and

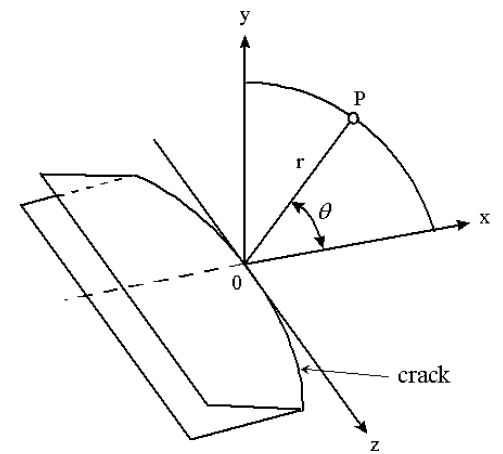

(a)

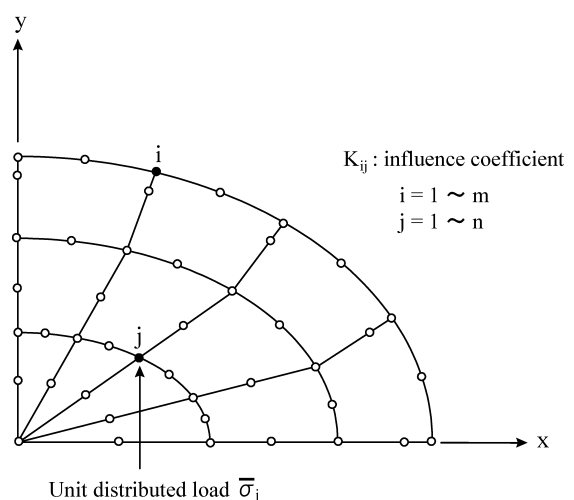

(b)

Fig. 1. Local coordinates at crack front (a) and definition of the influence coefficient $K_{i j}$ (b). Node $i$ is at the leading edge of the crack, and node $j$ is at the crack surface.

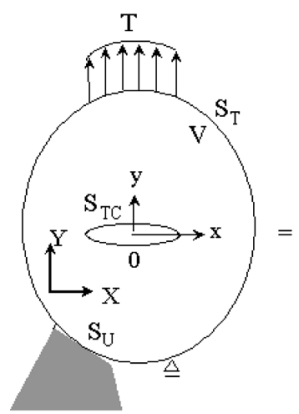

(a)

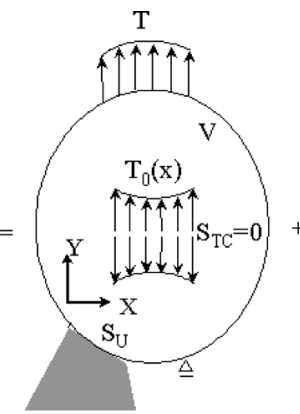

(b)

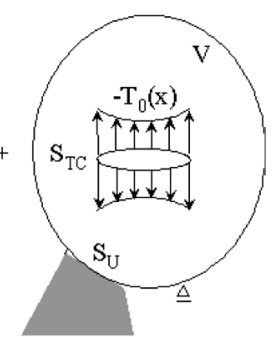

(c)
Fig. 2. Principle of superposition applied to the crack problem: (a) elastic body $V$ containing a crack under applied distribution stress $T$, (b) elastic body under applied distribution stress, and (c) crack interface $S_{\mathrm{TC}}$ under applied distribution stress $-T_{0}$.

the maximum value of $\sigma_{2}(X)$ is one. The applied stress $\sigma_{0}$ ranges from $\sigma_{\min }$ to $\sigma_{\max }$. Due to uniaxial tension, the constants $G, H, I, J$, and $K$ were zero, and the constant $L$ equaled unity.

The $K$ values at the leading edge of the subsurface crack were evaluated by using the algorithm for solving Eq. (1) and the strain extrapolation method ( $r \ll a$ in Fig. 1(a) $)^{3)}$; in this method, the method of least squares and the assumption of a plane strain condition without free surface were employed. The correction constant of the stress intensity factor $F$ is obtained as follows: 


$$
F=\frac{K_{\mathrm{I}}}{\sigma_{0} \sqrt{\pi a / Q}}, \quad Q=1+1.464\left(\frac{a}{c}\right)^{1.65}
$$

\subsection{Fracture Surface Analysis}

Fatigue crack initiation sites and fracture surfaces were analyzed by scanning electron microscopy (SEM). At low magnification the subsurface crack initiation sites appear flat and are inclined to the principal stress axis as shown in Fig. 3(a). In this study the subsurface crack initiation sites was defined as the whole of the inclined area which did not placed on the fatigue crack propagating plane. More detailed observation exhibits "Facet" and "Border" parts in the initiation site as shown in Fig 3(b). ${ }^{7)}$ Region B in Facet gives an appearance like microcrack growth in a radial pattern from region A. However, its appearance is obviously different from that of the fatigue crack propagating plane in low $\Delta K$ region. The initiation site, therefore, gave Stage I crack and was considered to correspond to that for an elliptical initial crack in a plate with a thickness $t$ (Fig. 4(a)) ${ }^{5)}$ The crack length $2 a$, crack width $2 c$, and distance from the surface of the specimen to the center of the elliptical crack $d$, were determined with an orthographic projection on the main crack propagating plane as shown in Fig. 4(b); the direction of the crack length was parallel to the initial crack propagation direction.

The maximum fatigue crack size in Stage II was determined from the ripple mark on fracture surface. Striations on the propagating plane were characterized experimentally to examine the crack growth rate $d a / d N$. The position of a striation, $x$ and $z$, and its depth $l(=a)$, on the fracture surface were determined as shown in Fig. 5(a); in the figure the crack front containing the striation was approximated as an ellipse. The ripple mark on the fracture surface was also approximated in a similar manner. All of the analyzed marks were located on a surface crack. Subsequently, the fatigue crack growth rate was directly measured from the striation as shown in Fig. 5(b), and the crack size determined from the position of the striation was used to obtain the stress intensity range, $\Delta K_{\mathrm{I}}=K_{\mathrm{Imax}}-K_{\mathrm{Imin}}$, using a linear fracture mechanics program, a version of SCAN for subsurface cracks. ${ }^{4)}$ The estimated stress intensity range at the rip-

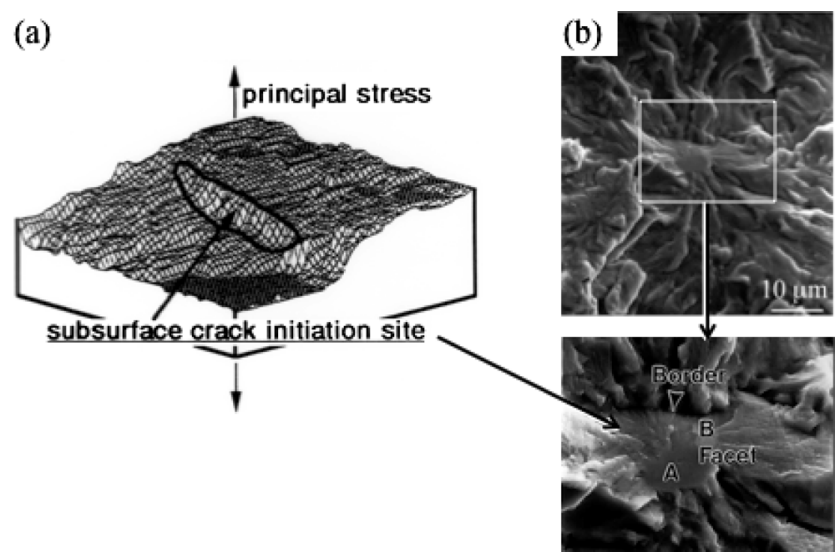

Fig. 3. Definition of subsurface fatigue crack initiation site: (a) three-dimensional indication (Normal, $4 \mathrm{~K}, \sigma_{\max }=1053$ $\mathrm{MPa}$ ) and (b) a secondary image showing a facet (Normal, $4 \mathrm{~K}, \sigma_{\max }=1235 \mathrm{MPa}$ ). ple mark was defined as $\Delta K_{\mathrm{f}}$.

\subsection{Simulation of Fatigue Crack Propagation Initiated from a Subsurface Crack}

The growth rate of a fatigue crack in a thick plate under uniaxial tensile stress is approximately given by the Paris

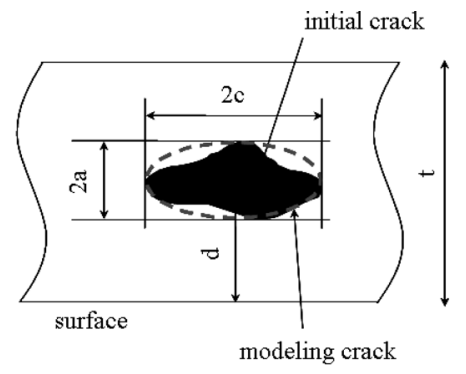

(a)

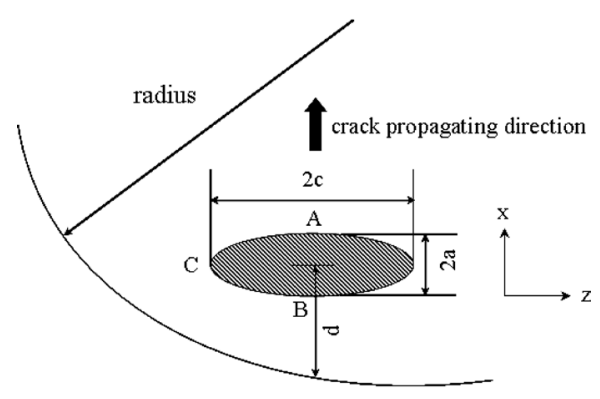

(b)

Fig. 4. Approximation of the initial crack as an ellipse (a) and definition of the size parameter for a subsurface crack (b)

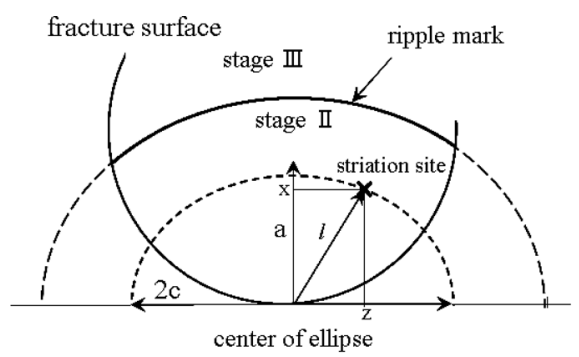

(a)

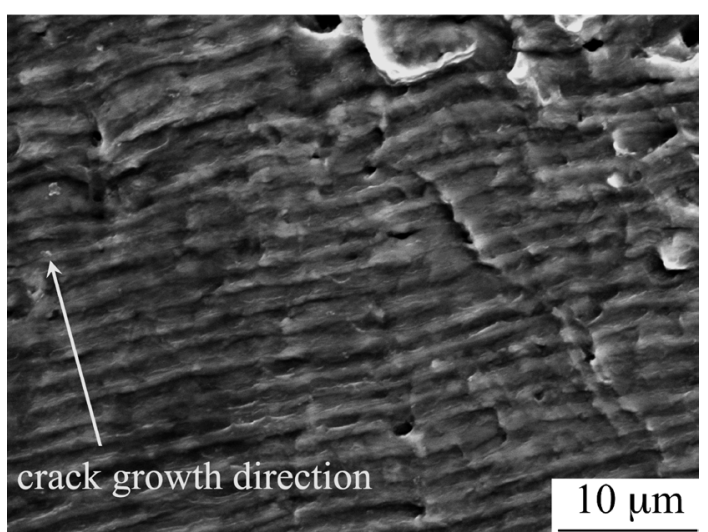

(b)

Fig. 5. Fractographic analysis of the fatigue crack growth rate and stress intensity range at the position of the striation (a) and a secondary image of striation (ELI, 4K, $\left.\sigma_{\max }=1115 \mathrm{MPa}\right)(\mathrm{b})$. 
rule $^{2)}$ as follows:

$$
\frac{d a}{d N}=C(\Delta K)^{m}
$$

where $C$ and $\mathrm{m}$ are constants. If the nonlinear effect of crack closure is neglected, $\Delta K$ in the alternating stress cycle can be evaluated for all combinations of $a / t$ and $a / c$ using the algorithm for solving Eq. (1). Subsequently, crack growth modeling was carried out on the basis of the Paris equation. The version of SCAN for subsurface cracks ${ }^{4)}$ was adopted to evaluate the value of $\Delta K$ of a subsurface crack. The initial as well as the maximum crack size were experimentally determined. The constants $C$ and $\mathrm{m}$ in Eq. (4) were assumed to be $5.07 \times 10^{-9}$ and 3.21 , respectively, for the test temperatures $4 \mathrm{~K}$ and $77 \mathrm{~K}$. These values were determined from crack propagation tests performed on a forged $\mathrm{Ti}-6 \mathrm{Al}-4 \mathrm{~V}$ alloy at cryogenic temperatures in Ref. 17).

The crack growth modeling was performed as follows:

(1) A subsurface crack initiation site approximated as an ellipse was adopted as the initial crack, as shown in Fig. $4(\mathrm{a}){ }^{4)}$

(2) The subsurface crack propagates by a certain amount after $\Delta N$ stress cycles. The crack remains elliptical in shape, although its aspect ratio a/c depends on the stress distribution. This assumption simplifies integration at the points $\mathrm{A}, \mathrm{B}$, and $\mathrm{C}$ in the crack growth modeling, as shown in Fig. 6(a). The points A and B represent the forward and backward directions of the length axis since the values of $F_{\mathrm{A}}$ and $F_{\mathrm{B}}$ apparently become different when the crack approaches the surface. The point $\mathrm{C}$ represents the width axis. Then, the crack is given in terms of $\Delta N$ as:

$$
\begin{aligned}
& \Delta a_{1}=C\left(K_{\mathrm{A}}\right)^{m} \Delta N \\
& \Delta a_{2}=C\left(K_{\mathrm{B}}\right)^{m} \Delta N . . \\
& \Delta a_{3}=C\left(K_{\mathrm{C}}\right)^{m} \Delta N
\end{aligned}
$$

where $\Delta a_{1}, \Delta a_{2}$, and $\Delta a_{3}$ are the amounts of crack growth in the directions $\mathrm{A}, \mathrm{B}$, and $\mathrm{C}$, and $K_{\mathrm{A}}, K_{\mathrm{B}}$, and $K_{\mathrm{C}}$ are the corresponding stress intensity factors, respectively.

(3) The shape of the propagated crack $\mathrm{A}^{\prime} \mathrm{C}^{\prime} \mathrm{B}^{\prime}$ is not elliptical, since the values of $\Delta a_{1}$ and $\Delta a_{2}$ are different. Therefore, it is approximated to a new elliptical crack with a length of $2 a^{\prime}=2 a+\Delta a+\Delta b$ and a width $2 c^{\prime}=2(c+\Delta c)$, as shown in Fig. 6(b).

(4) The center of the ellipse $O^{\prime}$, is determined, and its distance from the specimen surface, $d^{\prime}$, is calculated (Fig. $6(c))$.

(5) The above steps are repeated. The boundary between the subsurface crack and the surface crack during the stress cycles is defined by $c \leqq a+d$ (Fig. 7). ${ }^{5}$ The surface crack grows up to a crack length that satisfies the condition that $a / t=0.8$, where the thickness of the plate $t$ is approximately equal to the diameter of the specimen.

\subsection{Evaluation of Fatigue Life}

The number of cycles to failure $N f$ has been experimentally obtained. ${ }^{16)}$ The crack propagation life $N p$ was estimated by linear fracture analysis using SCAN. In the present study, the crack initiation life $\mathrm{Ni}$ is defined as:

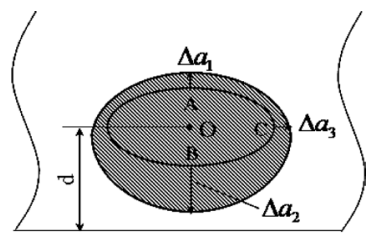

(a)

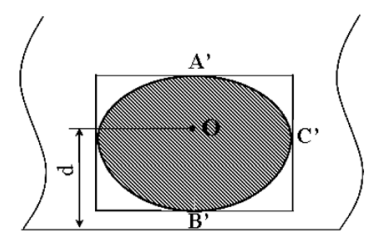

(b)

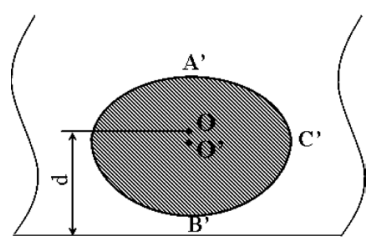

(c)

Fig. 6. Subsurface crack growth model: (a) growth of the crack, (b) approximation as an ellipse in the next step, and (c) resetting the center of the ellipse.

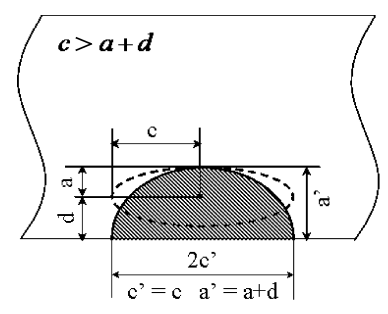

(a)

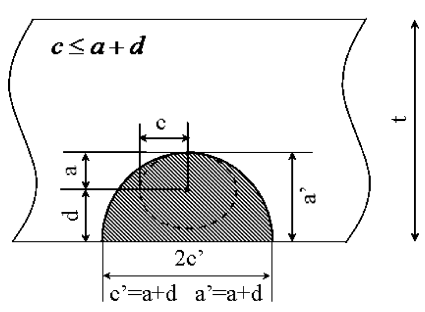

(b)
Fig. 7. Boundary condition from subsurface crack to surface crack under crack growth: (a) $c>a+d$, (b) $c \leqq a+d$.

$$
N i=N f-N p
$$

\section{Results and Discussion}

\subsection{Evaluated Crack Growth Life}

Figure 8 illustrates the size and location of the initial subsurface cracks in the samples. The initial subsurface crack length $2 a$ agrees with the threshold stress intensity range $\Delta K_{\text {th }}$ being a constant for crack propagation initiation (transition from Stage I to Stage II) regardless of the test temperatures $4 \mathrm{~K}$ and $77 \mathrm{~K}^{7}{ }^{7,18)}$ The initial subsurface crack width $2 c$ also exhibited the same trend (Fig. 8(b)). The distance from the surface of the specimen to the center of the ellipse d exhibited no dependence on the stress level (Fig. $8(\mathrm{c})$ ). The aspect ratio a/c slightly depended on the maximum cyclic stress $\sigma_{\max }$ and its average standard deviation was 0.33 (Fig. 8(d)). Equation (3) is modified as follows to give an approximate equation for obtaining the maximum stress intensity range $\Delta K_{\text {Imax }}$ at the subsurface crack tip as follows: 


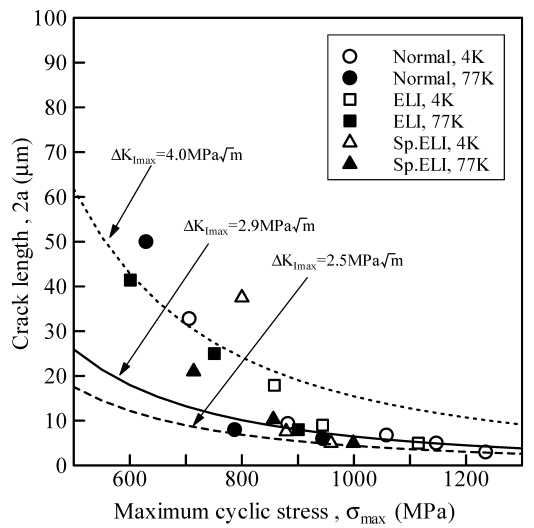

(a)

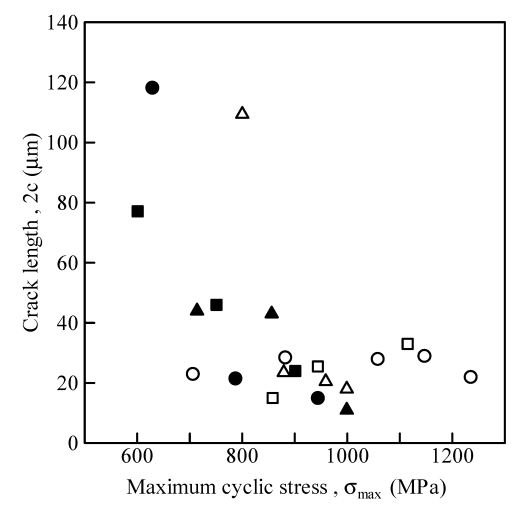

(b)

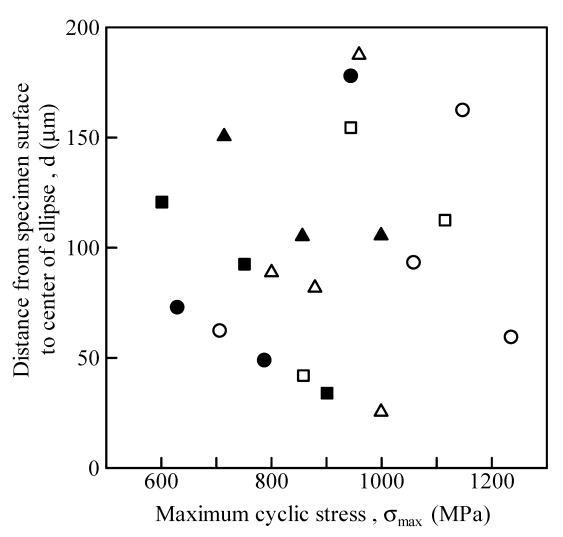

(c)

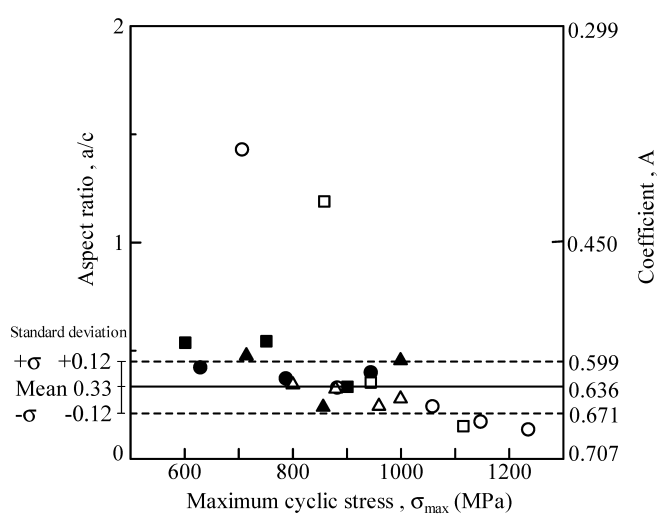

(d)

Fig. 8. Initial subsurface crack size and location: (a) crack length $2 a$, (b) crack width $2 c$, (c) depth from the surface of the specimen $d$, and (d) aspect ratio $a / c$ and coefficient $A$, according to Eq. (7). The curves in (a) indicate that the $\Delta K_{\text {Imax }}$ values of $2.5,2.9$, and $4.0 \mathrm{MPa} \sqrt{\mathrm{m}}$ are the estimated threshold values for crack propagation initiation.

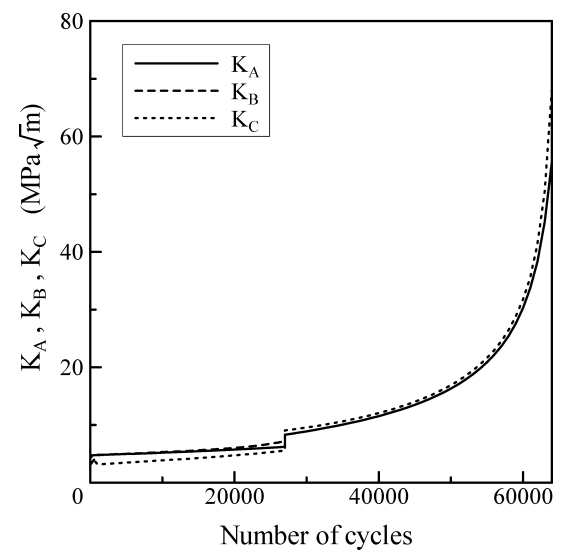

Fig. 9. Stress intensity factors of $K_{\mathrm{A}}, K_{\mathrm{B}}$ and $K_{\mathrm{C}}$ of a growing crack with cycles (Normal, $77 \mathrm{~K}, \sigma_{\max }=629 \mathrm{MPa}, 2 a=$ $50 \mu \mathrm{m}, 2 c=118 \mu \mathrm{m})$.

$$
\Delta K_{\operatorname{Imax}}=A \cdot \Delta \sigma_{\max } \sqrt{\pi \cdot 2 a}, \quad A=\frac{1}{\sqrt{2+2.928(a / c)^{1.65}}}
$$

where $\Delta \sigma_{\max }$ is the maximum cyclic stress range, and $A$ is a coefficient that depends on the shape of the subsurface crack. The average value of the coefficient was approximately 0.64 and it gave a value of $2.9 \mathrm{MPa} \sqrt{\mathrm{m}}$ for $\Delta K_{\text {Imax }}$ according to Eq. (7). The deviation indicated in Fig. 8 (d) gives a value of $\Delta K_{\text {Imax }}$ ranging from 2.5 to $4.0 \mathrm{MPa} \sqrt{\mathrm{m}}$ in the relationship between $2 a$ and $\Delta \sigma_{\max }$ as shown in Fig. 8(a). These values indicate that most of the subsurface crack initiation sites meet the relationship in the deviation. The value of $\Delta K_{\mathrm{th}}$ at the critical condition, wherein a subsurface crack leads to a fatal crack in a given stress range, has been estimated to be approximately $2.5 \mathrm{MPa} \sqrt{\mathrm{m}}$.

The propagation life of the initial subsurface cracks was evaluated using SCAN. Figure 9 presents a result of a crack growth simulation performed using SCAN for the normal grade alloy at $77 \mathrm{~K}$. At approximately $27000 \mathrm{cy}-$ cles, the transition from a subsurface crack to a surface one occurs; during the transition, the $K$ values increase discontinuously. The increases in the values of $K_{\mathrm{A}}, K_{\mathrm{B}}$, and $K_{\mathrm{C}}$ with the number of cycles were almost equal. Np was approximately 64000 cycles in the crack growth simulation, which was much lower than that of $N f$. Figure 10 summarizes the values of $N p, N f$, and $N i$ for all the samples. The value of $N p$ was less than a tenth of that of $N f$, which was more than $10^{6}$ cycles. In higher stress levels with a value of $N f$ less than $10^{6}$ cycles, the value of $N p$ in a few samples was approximately a fourth of that of $N f$. The value of $N p$ gradually increased as the stress level decreased, since the crack propagation (Stage II) regime developed into rapid fracture (Stage III) by attaining the critical stress intensity. However, the increase in the value of $N p$ was much lower than that of $N f$, as shown in Fig. 10. The subsurface crack initiation (Stage I crack generation) process under uniaxial cyclic stress consumes a large number of the cycles to failure-as many as that at a lower stress level. This demonstrates that the microstructure, such as the crystallographic orientation, morphology and size of grains, and microtexture, strongly affects the generation of a subsurface crack of critical size. The values of $\Delta K_{\mathrm{th}}$ and $N f$ depended on the mi- 


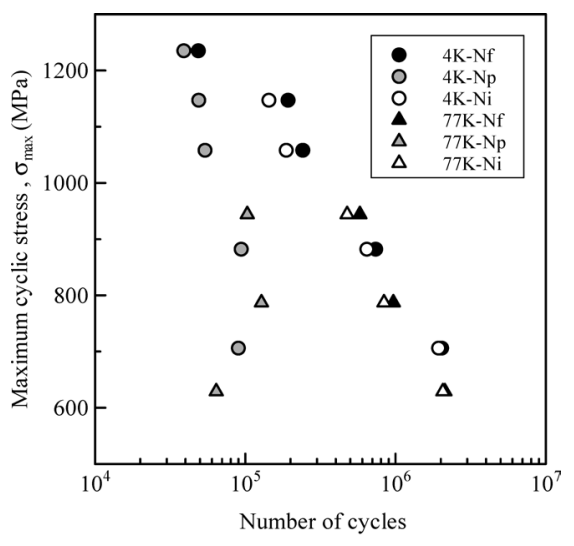

(a)

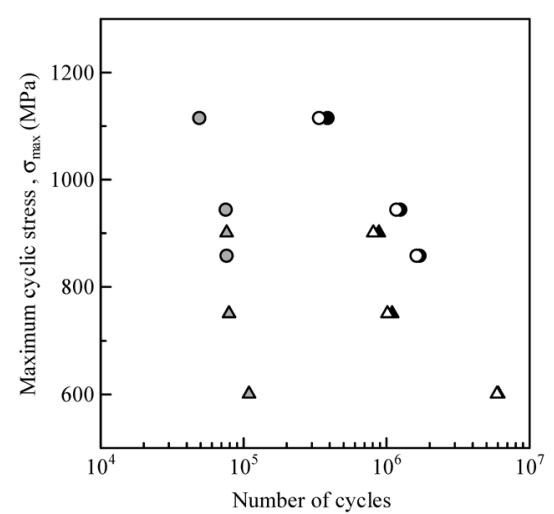

(b)

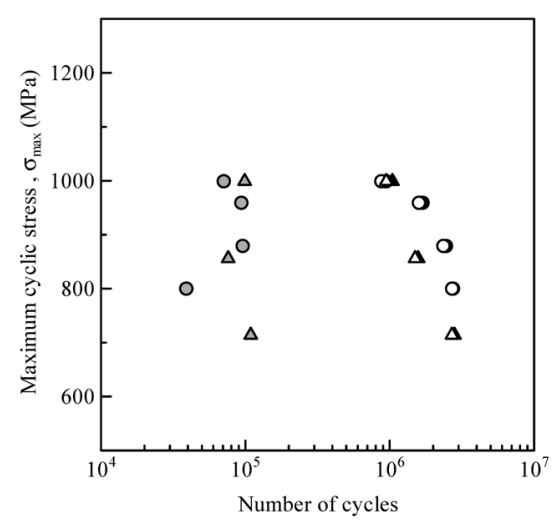

(c)

Fig. 10. $N p$ for the alloys of (a) Normal, (b) ELI, and (c) Sp.ELI grades at cryogenic temperatures.

crostructure.

\subsection{Crack Growth Analyses on the Fatigue Fracture Surface}

In order to estimate the errors in the calculated value of $N p$, we examined whether or not the evaluated value of $\Delta K$ agreed with a propagating crack on the fracture surface. First, the crack growth rate was characterized using the striations on the fracture surface as shown in Fig. 5(b). Figure 11 provides experimentally analyzed values of $d a / d N$ and the $\Delta K$ values. While striation analysis was performed in the high $\Delta K$ regime, the values of $d a / d N$ calculated using the Paris rule almost corresponded to the values of $d a / d N$ presented in Fig. 11. The values of $d a / d N$ for the three grades of alloy did not vary significantly.

Second, the ripple mark was presumed to correspond to

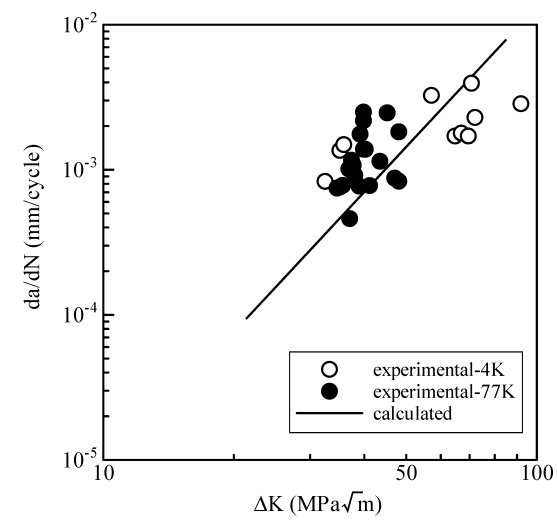

(a)

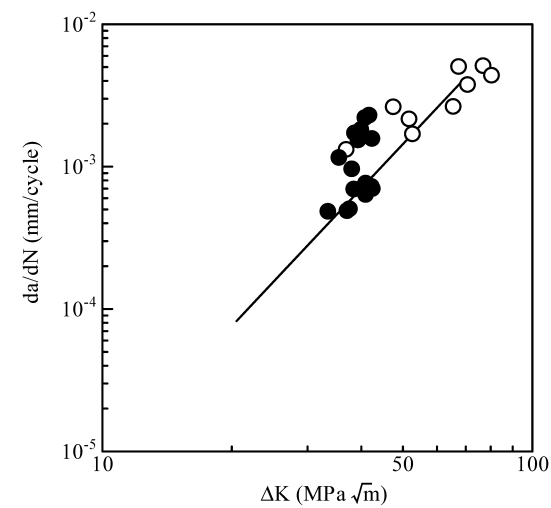

(b)

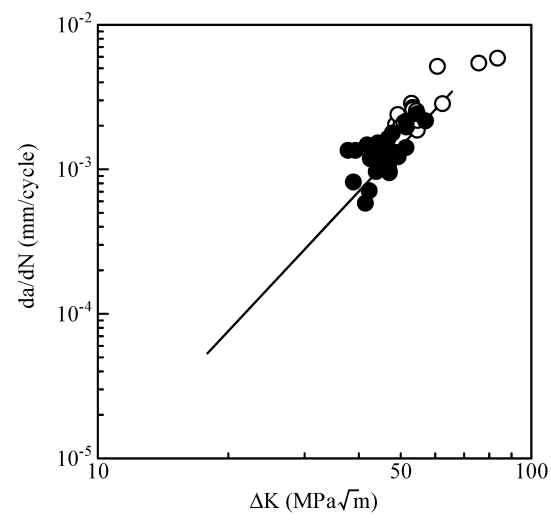

(c)

Fig. 11. Crack growth rate analyzed at the position of striations and estimated stress intensity factor range for (a) Normal, (b) ELI, and (c) Sp.ELI grades. Lines in figures represent results of the calculations.

the maximum fatigue crack, and, therefore, the maximum stress intensity range $\Delta K_{\mathrm{f}}$ in Stage II was estimated to evaluate errors in the values of $N p$. In the calculation performed using SCAN, crack growth occurred in a simple manner until the value of $a / t$ was 0.8 . The region of the fatigue crack growth indicated by the ripple marks was located on the specimen between circles with diameters 0.24 times and 0.6 times the specimen diameter as shown in Fig. 12(a). The ratio of the crack length at a ripple mark to the specimen diameter was found to increase as the maximum cyclic stress decreased. The $\Delta K_{\mathrm{f}}$ was estimated as shown in Fig. 12(b). The value of $\Delta K_{\mathrm{f}}$ varied from 42 to $106 \mathrm{MPa} \sqrt{\mathrm{m}}$ and showed a tendency to depend on the stress. Thus, it is difficult to adopt the value of $\Delta K_{\mathrm{f}}$ as the critical stress intensity leading to rapid fracture in this linear mechanics model. 


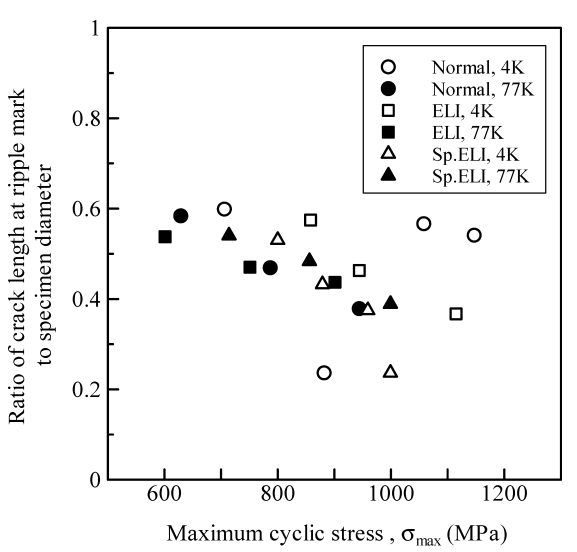

(a)

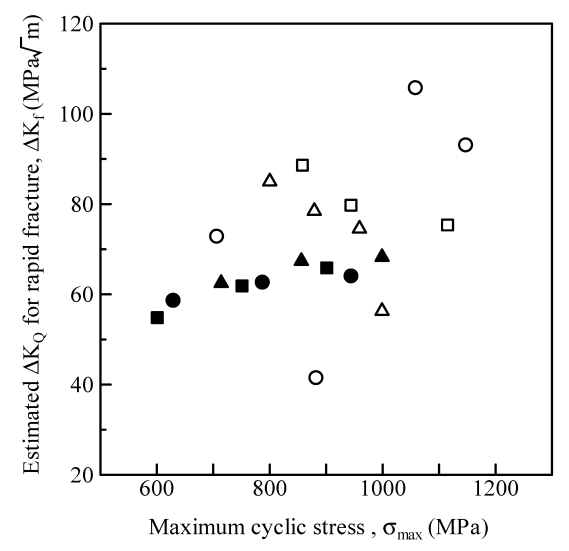

(b)

Fig. 12. Ratio of crack length at the ripple mark to the specimen diameter (a) and $\Delta K_{\mathrm{f}}$ for the alloys (b).

Furthermore, the value of $N p$ that corresponded to the maximum stress intensity range $\Delta K_{\mathrm{f}}$ was examined. The value of $N p$ obtained using SCAN was 1.02 times higher than that estimated from ripple marks, as shown in Fig. 13. The deviation, such as that indicated in Fig. 8(d), can be ignored for the evaluation of $N p$ in this modeling. Rapid fracture occurs when the ratio $a / t$ satisfies the condition for the critical stress intensity.

Thus, a modeling based on linear fracture mechanics and developed using SCAN can give a good estimate of the fatigue crack growth in $\mathrm{Ti}-6 \mathrm{Al}-4 \mathrm{~V}$ forged materials at cryogenic temperatures.

\subsection{Effects of Test Temperature and $R$ Ratio on Fa- tigue Crack Growth Rate}

Considerable data on crack propagation in Ti-6Al-4V alloys at room temperature are available, while data on crack propagation at cryogenic temperatures have been limited. Therefore, the evaluated relationship between $d a / d N$ and $\Delta K$ was evaluated using the reference data ${ }^{11-14)}$ since Ti-6Al-4V alloys exhibit a low-temperature deformation mode at and below room temperature. ${ }^{1,19)}$ The crack growth rates of Ti-6Al-4V forged materials at room temperature are statistically summarized along with their $R$ ratios, as shown in Fig. 14. The Paris constants $(C$ and $m)$ for $R$ ratio values of $0,0.5$, and 0.7 were $3.00 \times 10^{-9}$ and $3.72,2.00 \times$ $10^{-8}$ and 3.31 , and $7.00 \times 10^{-8}$ and 2.98 , respectively. The maximum cyclic stress level in the high-cycle fatigue regime is higher at lower temperatures. Figure 14 summa-

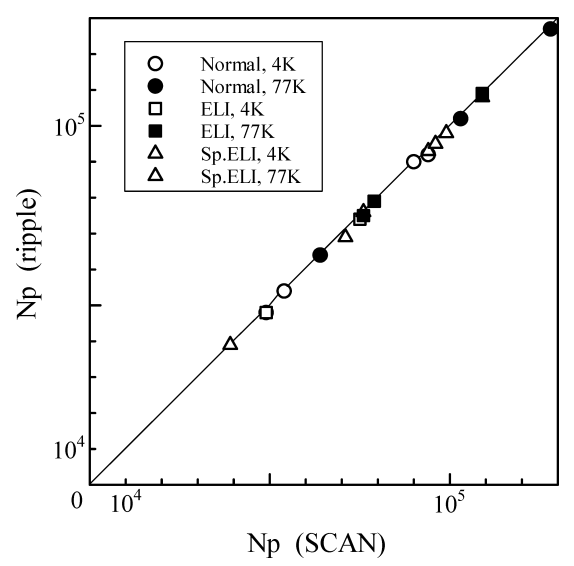

Fig. 13. Deviation of calculated crack propagation life conditional to surface crack growth up to $a / t=0.8$.

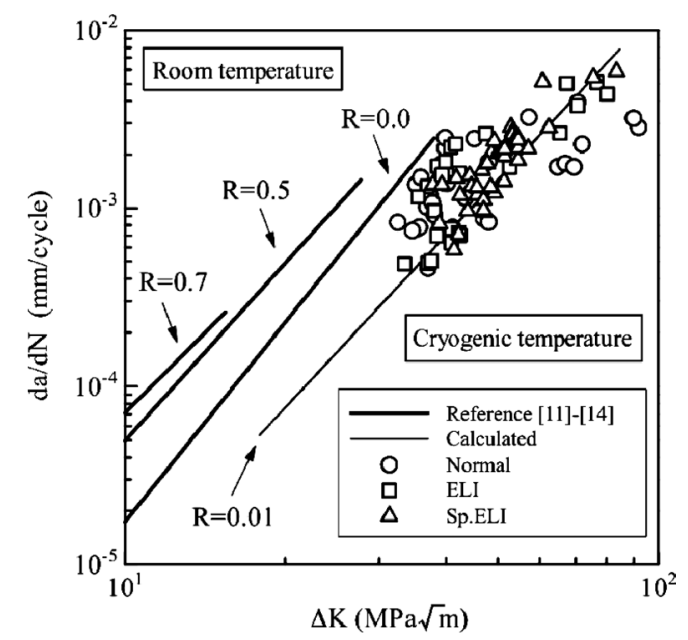

Fig. 14. Comparison of fatigue crack growth data for cryogenic temperatures with those for room temperature. ${ }^{11-14)}$

rizes stress levels on the basis of test temperature and stress ranges on the basis of $R$ ratio. The lines reflected both stress level by test temperature and stress range by $R$ ratio. If the size of a subsurface crack is given, the effects of the test temperature and $R$ ratio on the value of $N p$ can be roughly estimated through the proposed modeling method.

Microstructure also affects the fatigue crack growth rate in Ti-6Al-4V alloys. $^{9-14)}$ Fractographic features of fatigue crack growth have been correlated with the crystallographic orientation and deformation modes. ${ }^{20)} \mathrm{Ti}-6 \mathrm{Al}-4 \mathrm{~V}$ forged materials exhibited approximately the same morphology as aligned acicular or elongated $\alpha$ platelets, thus verifying the suitability of linear mechanics modeling to this study. ${ }^{7}$ However, the effects of size, morphology, and microtexture on fatigue crack growth modeling should be further examined.

\section{Conclusions}

Fatigue crack growth modeling was performed for $\mathrm{Ti}-$ $6 \mathrm{Al}-4 \mathrm{~V}$ forged materials failed by subsurface crack generation at cryogenic temperatures. The major results of this modeling are summarized below.

(1) Linear fracture mechanics analysis was used to estimate the crack propagation life under the Mode I crack growth condition using crack growth modeling. 
(2) The crack propagation life was estimated to be less than one-tenth the number of cycles to failure over $10^{6}$. In contrast, the subsurface crack initiation (Stage I crack generation) process under uniaxial cyclic stress consumed a large number of cycles to failure - as many as that at a lower stress level-leading to the conclusion that the number of cycles to failure may strongly depend on the microstructure.

(3) The values of $d a / d N$ calculated by the Paris rule approximately corresponded to those obtained from striation analysis. The value of $\Delta K$ agreed with the propagation of crack on the fracture surface.

(4) Modeling based on linear fracture mechanics can give a good estimate of the fatigue crack growth in Ti-6Al$4 \mathrm{~V}$ forged materials at cryogenic temperatures.

(5) Estimation of the effects of the test temperature and $\mathrm{R}$ ratio on the crack propagation life is possible using reference data obtained at room temperature.

\section{Acknowledgement}

We thank Prof. M. Shiratori and Mr. F. Iwamatsu for their provision of SCAN subsurface crack version.

\section{REFERENCES}

1) O. Umezawa and K. Nagai: ISIJ Int., 37 (1997), 1170.

2) P. C. Paris and F. Erdogan: Trans. ASME Ser. D, J. Basic Eng., 85 (1963), 528.

3) M. Shiratori: Current Topics in Computational Mechanics, ed. by J. F. Cory, Jr. and J. L. Gordon, ASME, New York, (1995), 357.
4) S. Nakanishi, F. Iwamatsu, M. Shiratori and H. Matsushita: Proc. Pressure Vessels and Piping 2006, ASME, New York, (2006), 1.

5) ASME Code Section XI, Rules for In-service Inspection of Nuclear Power Plant Components, ASME, New York.

6) The Japan Welding Engineering Society: WES 2805-1997, Method of Assessment for Flaws in Fusion Welded Joints with Respect to Brittle Fracture and Fatigue Crack Growth, Tokyo, (1997).

7) O. Umezawa, K. Nagai and K. Ishikawa: Tetsu-to-Hagané, 76 (1990), 924.

8) H. Kitagawa, S. Takahashi, C. M. Suh and S. Miyashita: Fatigue Mechanisms, STP675, ASTM, West Conshohocken, (1978), 420.

9) A. W. Bowen: Acta Metall., 23 (1975), 1401.

10) S. Dubey, A. B. O. Soboyejo and W. O. Soboyejo: Acta Mater., 45 (1997), 2777.

11) A. W. Thompson, J. C. Williams, J. D. Frandsen and J. C. Chesnutt: Titanium and Titanium Alloys, Scientific and Technological Aspects, Vol. 1, ed. by J. C. Williams and A. F. Belov, Plenum Press, New York, (1982), 691.

12) G. Lutjering and A. Gysler: Titanium Science and Technology, Vol. 4, ed. by G. Lutjering, U. Zwicker and W. Bunk, Deutsche Gesellschaft für Metallkunde, Frankfurt, (1985), 2065.

13) G. R. Yoder, L. A. Cooley and T. W. Crooker: Metall. Trans. A, 9A (1978), 1413.

14) A. Yuen, S. W. Hopkins, G. R. Leverant and C. A. Rau: Metall. Mater. Trans., 5 (1974), 1833.

15) P. Neumann: Acta Metall., 17 (1969), 1219.

16) K. Nagai, T. Yuri, T. Ogata, O. Umezawa, K. Ishikawa, T. Nishimura, T. Mizoguchi and Y. Ito: ISIJ Int., 31 (1991), 882.

17) T. Yuri, Y. Ono, H. Sumiyoshi and T. Ogata: Proc. of 71st Cryogenic Engineering Meeting, Tokyo, (2004), 240.

18) O. Umezawa and K. Ishikawa: Mater. Sci. Eng. A, A176 (1994), 397.

19) R. K. Steele and A. J. McEvily: Eng. Fract. Mech., 8 (1976), 31.

20) Y. Mine, S. Ando, K. Takashima, H. Tonda and Y. Higo: J. Jpn. Inst. Met., 61 (1997), 41. 